\title{
Can plastics be ever replaced in the dairy industry?
}

\author{
Pallavi Ratha, Noyonika, Deepak Chaurasiya and Gautam Kaul*
}

Right from the advent of industrialization and commercialization of food products, safe packaging and transport have always been of immense importance. Materials that are relatively resistant to environmental wear and tear, are chemically neutral along with being easy and profitable to manufacture have always been preferred. Over time many such ideas and innovations for safe and profitable packaging have come and gone. Starting from leaf plates to stainless-steel cans to aluminum-foil cases, packaging has come a long way. Although none of these matches with the en vogue commercial, omniscient packaging material, viz. 'plastic'. Be it durability, multipurpose use, or being the big cause for widespread garbage and pollution, plastic tops it all. However in the 21st century and in the current world scenario, along with the desired industry-required characteristics, a substance leaving minimum carbon footprint is of utmost demand.

Keywords: Bio-based polymers, dairy industry, pet bottles, plastics.

\section{What is plastic and why such an uproar for its removal}

PLASTIC is a name for a wide array of synthetic or semisynthetic organic biopolymers of petrochemical origin. The polymer being organic links to its chemical nature and not to its biological degradability, something that can be easily confused with. The bonds between the monomers in these polymers are quite strong and resistant. Hence, even if it is deemed 'organic', the polymer cannot be degraded by decomposers and thus stays in the environment forever causing pollution. Every year, it adds to the total load of garbage on the earth due to its slow degradation process. Common methods of disposal are a nuisance in this case as its incineration leads to dense toxic fumes, with water and other forces of nature having little or no effect on it, leaving us with a management crisis to clean the environment and tougher still, find a replacement for plastics.

\section{Plastics in dairy industry}

Dairy industry is one of the most important and prominent components ${ }^{1}$ of the food industry not only in India but world over (Table 1). Owing to its economic, industrial and strategic viability, plastic has been an integral part of this industry. Plastics do not react with the dairy

Pallavi Ratha, Deepak Chaurasiya and Gautam Kaul are at the ICARNational Dairy Research Institute, Karnal 132 001, India; Noyonika is in the ICAR-Indian Institute of Wheat and Barley, Karnal 132 001, India.*For correspondence. (e-mail: gkndri@gmail.com) products and thus add to their shelf life. Impenetrable as they are, external microbial contamination is also not that prevalent. All these factors have contributed to a tremendous boost in the widespread use of plastics in the dairy industry, especially in India. Non-plastic materials being used in the dairy industry in the country are virtually negligible, if not nil.

Starting from ice-cream cups to large-scale milk packaging, plastic is used everywhere (Table 2). A large variety of packages are being circulated at present to cater to the diverse needs of the population ${ }^{2}$. Industries generally use either flexible or rigid packaging. In the non-dairy food industry, both flexible and rigid packaging are widely used. Flexible packaging uses multilayer or monolayer films of plastic. The multilayered variety mainly includes polypropylene (PP), polyethene (PE), polyethylene terephthalate, polyvinyl chloride, with $\mathrm{PE}$ and PP being a part of about $62 \%$ of polymer usage. With increasing population and increase in food demand, the expected growth rate of the Indian packaging industry is about $15 \%$ p.a. with rigid packaging growing at about $14 \%$ p.a.

Table 1. Indian dairy industry $(2019)^{1}$

$\begin{array}{ll}\text { Total dairy industry } & \text { Rs } 7 \text { lakh crores } \\ \text { Pouch milk industry } & \text { Rs } 1.3 \text { lakh crores } \\ \text { Polyfilm (quantity for milk) } & 1.5 \text { lakh million tonnes } \\ \text { Polyfilm value } & \text { Rs } 1600 \text { crores }\end{array}$

Plastics used in the Indian dairy industry comprise a sizable chunk of its economy, with the requirements increasing with time, keeping pace with the growing consumer demands. The table indicates the said parameter from data of the year 2019. 
Table 2. Liquid milk packaging $(6 \text { crore litres/day })^{1}$

\begin{tabular}{lccc}
\hline & Weight/1 $(\mathrm{g})$ & $\begin{array}{c}\text { Total quantity/year } \\
\text { (lakh million } \\
\text { tonnes) }\end{array}$ & $\begin{array}{c}\text { Total } \\
\text { value/year } \\
\text { (Rs crores) }\end{array}$ \\
\hline Glass bottles & 650 & 142 & 37,000 \\
PET bottles & 75 & 16 & 24,000 \\
HDPE & 45 & 10 & 13,000 \\
Jerry can & 5 & 1 & 1,600 \\
LDPE film & & & \\
pouch & & & \\
\hline
\end{tabular}

This is a snapshot of the amount and cost of packaging used for packing of 6 crore litres of milk per day. The amount of each packaging item needed per litre of milk throws light on its efficiency; and the LDPE film pouch proves to be the best.

\section{Data and statistics}

A lot has been said at various platforms about plastics. However, there appears to be a lack of credible data to build a case for its replacement or even continuance. Thus it is difficult to propose any long-lasting solution to this problem. One estimate mentions that since the 1950s, plastic wastes of about 1 billion tonne volume has been discarded ${ }^{3}$. However, the recycling rate is only $9 \%$ of the average human production of 6.3 billion tonnes of plastic. Much of this material may persist for centuries or longer, given the demonstrated persistence of structurally similar natural materials such as amber.

Ocean Conservancy, USA has reported that China, Indonesia, the Philippines, Thailand and Vietnam dump more plastic in the sea than all other countries combined, India luckily is excluded from the list ${ }^{4}$. The rivers Yangtze, Yellow, Indus, Nile, Hai, Pearl, Ganges, Amur, Niger and Mekong transport $88-95 \%$ of the total global plastic load into the sea ${ }^{5}$. It is surprising that there is mention of only one river from India, the Ganges, given the vast demography along with the huge plastic consumption and production of our country.

Natural microorganisms are not evolved to efficiently decompose petroleum-based polymers. The average amount of energy required for the production of biobased polymers is less than petrochemical polymers (57 MJ/kg compared to $77 \mathrm{MJ} / \mathrm{kg}$ ) and are therefore more beneficial to the problem at hand, i.e. global warming. With such similarities in functions between the conventional and biological polymers, bio-based polymers have emerged as an ideal option in the field of environmental sustainability ${ }^{6}$.

More than the macro form, microplastics have been a greater source of concern ${ }^{7}$. The concentration of microplastics in the gut of seabirds has been increasing since the 1960s.

It is now well established that there is a high degree of possible pathogenicity of the inherent milk flora with abiotic surfaces in the dairy industry. Despite studies revealing that among all the materials used in the dairy industry, the hydrophobic surfaces have a greater tendency to promote microbial attachment and subsequent biofilm formation, the persistent use of plastics is continuing.

Biofilm formation is an important step in the process of pathogenesis of many well-known harmful bacteria ${ }^{8}$. Thus instead of known hydrophobic surfaces that are intensively used in the dairy industry (e.g. PVC, polystyrene, polypropylene, etc.), better alternatives must be given serious consideration keeping in mind the economic as well as environmental concerns.

\section{Initiatives to address the cause}

There has been a worldwide campaign to eradicate single-use plastics and replace them with environmentfriendly alternatives. In India, some big companies have already come up with policy plans to combat this issue after the Prime Minister launched a month-long awareness programme which ended with much fanfare on 2 October 2019. The dairy industry was asked to halve its plastic usage and consider biodegradable options. PET bottles with less than $200 \mathrm{ml}$ volume and plastic packets with less than $500 \mathrm{ml}$ volume have been seen to precede the complete replacement of plastic ${ }^{9}$.

Use of paper straws, wooden spoons and economical bio-based polymers has already been started by many industries. Several other steps have been taken by the Government and also by conglomerates alike to address this problem.

Bio-based polymers made from whey and casein are popular and can be readily used in the dairy industry, given the low investment in raw materials and commercial viability ${ }^{5}$. The starting materials are basically obtained from waste sludge during the manufacture of other dairy products and thus can be used directly from the industry itself, a big nod to the $3 \mathrm{R}$ principle of environmental conservation.

The Bottle Project is a research funded by the European Union which provides innovative environmental solutions to packaging in the dairy industry. With an aim to manufacture two types of bottles, different biomaterials have been manufactured to be used as raw materials for the manufacture of these 'bio-plastics'. The project consortium, coordinated by implants, consists of eight companies from five different countries, viz. Portugal, Spain, Italy, Germany, and Belgium, combining the appropriate capabilities and expertise along the value chain. Several commercial biodegradable materials which have been developed to address the same aspect show some limitations. In contrast, popular packaging materials like high density polyethylene (HDP) used in food contact applications like dairy products, are the primary focus of the biobottle project. However, the major drawbacks are low thermal and mechanical properties, which are much needed from the packaging and marketing points of view. 

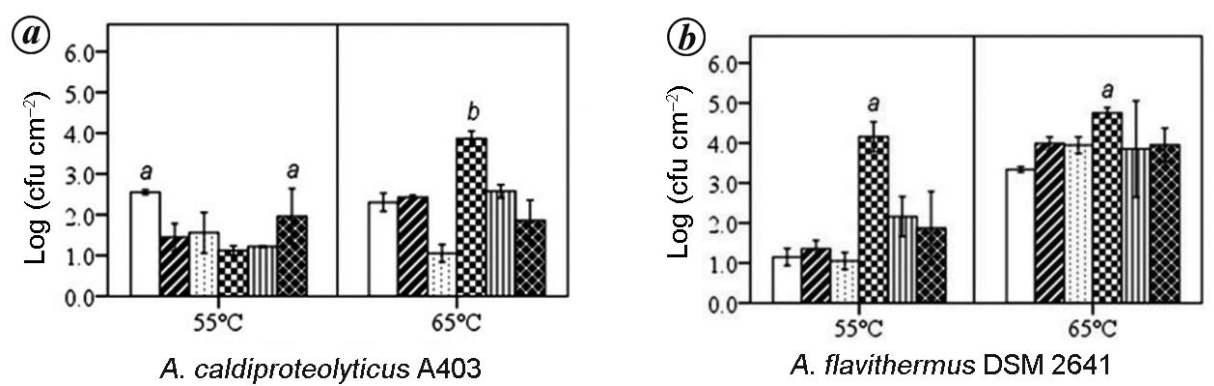

A. flavithermus DSM 2641
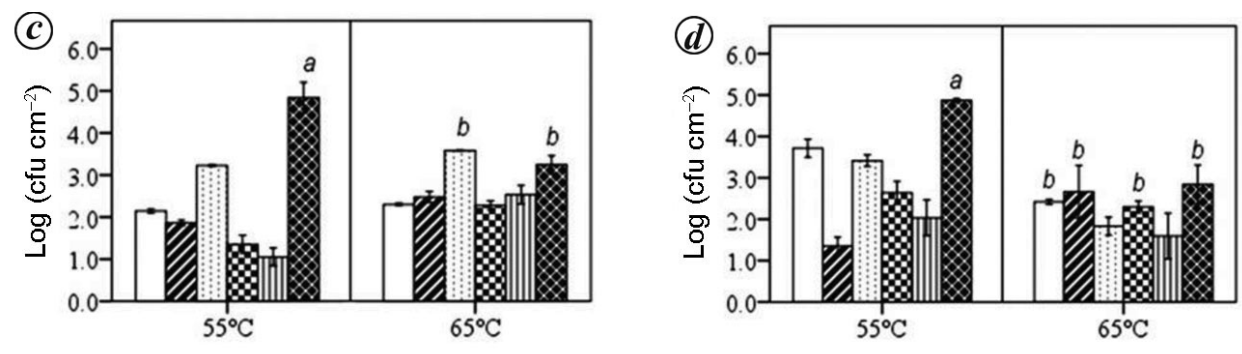

A. kamchatkensis subsp. asaccharedens $\mathrm{F} 81$

A. tepidamans DSM 16325

Figure 1. Total Anoxybacillus counts in whole milk attached to different abiotic surfaces at $55^{\circ} \mathrm{C}$ and $65^{\circ} \mathrm{C}$. Error bars indicate SD of duplicate experiments. The letters ' $\mathrm{a}$ ' and ' $\mathrm{b}$ ' above the columns in a subfigure represent significantly higher counts $(P<0.05)$. The same letters like aa, bb in a sub-figure indicate that there is no difference between the surfaces ${ }^{8}$.

These limitations are being solved in vivo, where suitable biodegradable materials are being developed to obtain three different types of packages for dairy products. These packages are improved with new enhanced characteristics: thermal resistance, processability, functionality and biodegradability. They are viable, legal and can be composted easily. These biomaterials comply with the legal requirements based on plastics for food contact. The compounds developed by chemically modifying reactive extrusion allow obtaining packages which are all stable at temperature up to $75^{\circ}$ Celsius (during the pasteurization process). In this process, chemical bonds are formed between the polymer chains resulting in a dense network of very high molecular weight polymers, which become less mobile when subjected to thermal or mechanical stress. Also, properties like heat distortion, Environmental Stress Crack Resistance, creep and abrasion resistance are enhanced. The processed biomaterials need not be separated from organic waste at the end of their brief cell life. In addition, traditional plastic processing equipment can be used to manufacture this product, thus requiring no extra machinery cost.

AIMPLAS (Spain) was able to obtain compounds with the same properties which included thermal stability and abrasion resistance. Each material was accurately designed for individual package product processing. The process to obtain pouches was carried out in two steps: the first was brown film extrusion and the second was moving it to the back-performance stage in the production process. Both bottle types were obtained by extru- sion blow moulding. The $500 \mathrm{~mm}$ bottles were obtained by the special blast facilities in Portugal using a singleextrusion head. In order to complete the biodegradable big bottle ensemble, a cap was placed across the side. The cap obtaining was carried out using a conventional injection moulding equipment. The validation, coordinated by CN Air, Italy, was based on the functional, microbiological and organoleptic analysis and legal requirements for food contact. The organoleptic analysis was performed by a professional consumer panel. The FDA legal requirements based on migration aspects were analysed by VLB, Germany. Combustibility test according to EN134322 was done by OWS, Belgium, and the compound will be certified by Vincent. The materials which can be disposed together with organic waste are found to decompose in the regulated combustible plants into biomass: $\mathrm{CO}_{2}$ and water in less than six months. Thus this project can be a leading study for the production of biodegradable packaging materials with enhanced thermal and mechanical resistance for the production of different types of bottles and pouches, especially for the dairy industry.

In another unique research application, scientists have found a way to make casein protein less susceptible to cracking, while processing it for making cases and coverings. The method simply uses silicate clay by the name sodium montmorillonite. After subjecting sodium montmorillonite to freezing temperatures, it gets converted into an aerogel, a sponge-like material ${ }^{10}$. Then it is infused with the porous network of clay with casein plastic as a result of which a polystyrene-type material is formed, 


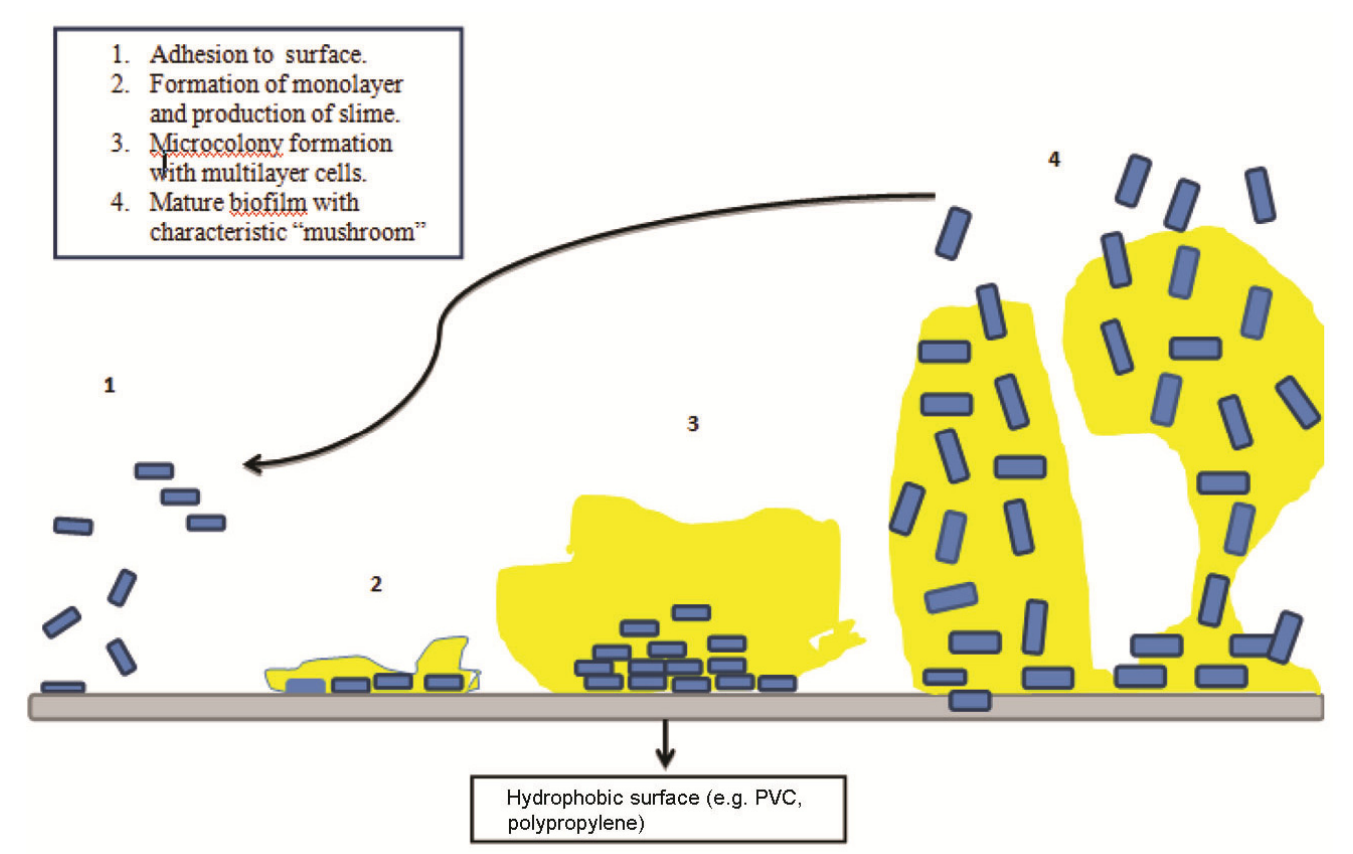

Figure 2. A biofilm is a three-dimensional aggregate of single or multiple types of microorganisms that is submerged in auto-generated Extracellular Polymeric Substances (the slime) and is generally adhered to a surface. The EPS is basically composed of polysaccharides in structural roles along with junk materials from the surrounding environment, like RBC, soil particles, etc. Biofilm formation is a step by step process that results in a system where the participating micro floras are interdependent on each other for nutrients, better known as a syntrophic consortium. Generally, motile bacteria constitute these biofilms, as the nonmotile bacteria cannot recognize the surfaces or aggregate as easily for successful attachment. Increased hydrophobicity is also found to account for low resistance between the surface and the bacterium, thus aiding the commencement of the biofilm formation.

which is excellently biodegradable. The product is also relatively less toxic, as in the manufacturing process, glyceraldehyde is substituted for formaldehyde.

\section{Solutions for the dairy industry to consider}

Innovative minds have always been at work and have come up with several outstanding solutions to address the problem at hand ${ }^{11}$. These ideas carry immense potential to completely replace plastics in the dairy industry ${ }^{12,13}$. Some of these are mentioned below.

\section{Bio-based polymers}

These are made from waste products from the production of corn. They are easy to produce, manage and can be made into a wide array of products for use in the dairy industry, like food-grade plastics, wrap films, etc. Similarly, polymers made from mushroom root, bagasse and stone plastics are excellent alternatives (although in a developing nation like ours, the question remains: food for the poor or plastic alternative?).

\section{Milk plastics}

Milk-based plastic-like packaging substances are not new in the market. In fact, in the old times, a similar method was adapted along with other biodegradable packages. Plastics made from casein molecules as mentioned earlier, combined with clay and glyceraldehyde can be good way to replace plastics in dairy packaging. Whey protein residues have also been found to have beneficial packaging potential.

\section{Leaves}

Leaf-based packaging is an age-old practice in India and it can be revived to be used in the short-term packaging of certain dairy products like paneer, milk powders, etc. Several plant varieties have impervious waxy leaves (like sal leaf) that can be successfully utilized for the same.

There are a few alternatives that are in the running phase and can be immediately implemented.

\section{PET bottles and Tetra-Pak}

Tetra Pak TBA cartons are six-layered packages with paper-based products, aluminium foil and polythene as components. Although in successful running use, they are still a threat to the environment as trees need to be cut to produce them. PET bottles are plastics too, but since their resale values are high, they tend to get collected and thus can be reused or recycled according to the requirement. 
As climate change becomes more and more prominent with each passing day, our need to go 'green' gains more spotlight. The marketed products need packaging basically for their durability and safety. With the advent of plastic packaging materials, it has become a challenge to develop a material that would compete with the conventional plastics in terms of mechanical and thermal durability, easy manufacturing and handling, docility, etc. along with being biodegradable ${ }^{14}$. Some well-known companies have developed unique ecofriendly packaging techniques.

\section{$I K E A$}

This Swedish furniture company has adopted mushroombased packaging in its search for a biodegradable alternative. Outer roots and shell of the mushroom consists of mycelia, which when mixed with oats provides a solid packaging material (fit to transfer precious glassware too). In the dairy industry, this type of packaging can be used to transfer fragile dairy products like biodegradable milk pouches.

\section{Veuve Clicquot}

This champagne house in France uniquely uses potato as a part of Naturally Clicquot, its new product. This champagne range comes with an ecofriendly packaging made using potato starch. This too can be used in the dairy industry to transport fragile packages. Veuve Clicquot has also used grape skins in its biodegradable packaging project.

\section{Woolcol}

This company in the UK produces sheep wool-based insulated packaging. This idea can be extensively applied in the dairy industry considering the market demand for warm dairy products like fresh milk.

\section{RHYTHM-108}

This company in Switzerland has introduced a biofilm Natureflex made from wood pulp extracts of the eucalyptus trees. Biofilms can be and are already being used extensively in dairy packaging.

\section{American Chemical Society}

The society is the process of developing a biodegradable, edible packaging made from milk protein, i.e. casein. This film is found to be about 500 times better than plastic in preventing exposure of wrapped food to oxygen. Dairy industry may soon become self-reliant in its need for biodegradable packaging materials with the introduction of this biofilm.

\section{Whole Tree}

Coconut husk has been used as a packaging and stuffing material since ages, due to its tough lignin-based structure and natural burn resistance. Whole Tree, Texas, USA is using this as an alternative to plastic packaging.

Although these methods seem impractical from a commercial point of view, such changes when brought about slowly into the market can help create a niche and lessen the demand for plastics.

\section{What we can do to contribute}

We cannot entirely replace plastics in the dairy industry as such, but we can always follow the $3 \mathrm{R}$ rule, reduce, reuse and recycle, and also do not litter. Simple change in habits like using dustbins, replacing any single-use commodity with reusable ones can do wonders. Instead of using paper-based products which will aggravate and compound another problem, it is better to incorporate recycled and multipurpose goods with natural degradation time frame, as paper degrades faster, and manufacturing and recycling of paper is no more environment-friendly than plastic. Use of glass bottles at home and stainlesssteel flasks while travelling, replacing utensils with stainless steel, brass, glass and porcelain instead of harmful bakelite and melamine, swapping polythene bags for cloth bags are some of the ways that we can contribute. We can carry our own bags or utensils while shopping for dairy products ${ }^{15}$.

\section{Conclusion}

We need to consider whether with all these possible alternatives, it is actually sustainable or feasible to halve the plastic use in the next year or so. Is the alternative of bio-based polymers or reusable glass bottles or other similar 'environment-friendly' methods actually viable economically or otherwise to the industries in a large scale? We can cautiously say 'yes', despite some reservations by the stakeholders of all strata in the dairy industry. A vision to tackle the economic scenario upon plastic replacement as well as to pave the way for a better environment-friendly and healthy future environment is the need of the hour. Research, laws, advisories, etc. can only do little if proper orientation for change is absent. Right now, we have to work together to make bio-based polymers in the dairy industry commercially and economically sustainable. With proper measures and the right attitude, complete and successful replacement of plastic from the dairy industry may not be a distant hazy dream. 
1. Sodhi, R. S., Plastic packaging for Milk and other food products, Indian centre for plastics in the environment, Amul Corporation, 2019; http://icpe.in/pptdelhi/SS\%20Indian\%20Centre\%20for\%20Plastics\%20in\%20the \%20Environment-1\%20\%20R\%20S$\% 20$ Sodhi.pdf

2. How stuff works, top 10 eco-friendly substitutes for plastic, 2009; https://science.howstuffworks.com/environmental/green-tech/ sustainable/5-plasticsubstitutes.htm/ (accessed on 5 April 2020).

3. Kilker, J., The world without us. Sci. Commun., 2008, 30(2), 288291.

4. Schmidt, C., Krauth, T. and Wagner, S., Export of plastic debris by rivers into the sea. Environ. Sci. Technol., 2017, 51(21), 12246-12253.

5. DW, Environment, all plastic in the ocean comes from just 10 Rivers. 2017; https://www.dw.com/en/almost-all-plasticin-the-oceancomes-from-just-10-rivers/a-41581484/ (accessed on 6 April 2020).

6. Song, J. H., Murphy, R. J., Narayan, R. and Davies, G. B., Biodegradable and compostable alternatives to conventional plastics. Philos. Trans. R. Soc. London, Ser. B, 2009, 364(1526), $2127-$ 2139.

7. Ralston, B. E. and Osswald, T. A., The history of tomorrow's materials: protein-based biopolymers. Plast. Eng., 2008, 64(2), 36-40.

8. Karaca, B., Buzrul, S. and Coleri, C. A., Anoxybacillus and Geobacillus biofilms in the dairy industry: effects of surface material, incubation temperature and milk type. Biofouling, 2019, 35(5), $551-560$.
9. Zhang, J., Jiang, L., Zhu, L., Jane, J. L. and Mungara, P., Morphology and properties of soy protein and polylactide blends. Biomacromolecules, 2006, 7(5), 1551-1561.

10. Markande, A. R. and Nerurkar, A. S., Biochemical diversity of microbial bioemulsifiers and their roles in the natural environment. Research Gate, 2014.

11. Barnes, D. K., Galgani, F., Thompson, R. C. and Barlaz, M., Accumulation and fragmentation of plastic debris in global environments. Philos. Trans. R. Soc. London, Ser. B, 2009, 364(1526), 1985-1998.

12. Formerly innovation excellence, 13 plastic packaging alternatives, 2008; https://disruptorleague.com/2018/07/02/13-plastic-packagingalternatives/ (accessed on 5 April 2020).

13. https://www.business-standard.com/article/economy-policy/singleuse-plastic-banindustry-mulls-polyester-yarn-for-milk-packaging119093001410 1.html/ (accessed on 5 April 2020).

14. Business-standard, single-use plastic ban: industry mulls polyester yarn for milk packaging, 2019; https://www.economist.com/ science-and-technology/2010/10/28/there-and-back-again/ (accessed on 5 May 2020).

15. FICCI, A report on Plastics Industry, 2018; https:// plastindia.org/pdf/Indian-Plastics-Industry-Report-2018-2.pdf/ (accessed on 6 May 2020).

Received 8 May 2020; revised accepted 1 September 2020

doi: $10.18520 / \mathrm{cs} / \mathrm{v} 119 / \mathrm{i} 9 / 1411-1416$ 